\title{
A propósito de los «Libros decimosexto y decimoséptimo» de los Comentarios de erudición, de Bartolomé Jiménez Patón: notas léxicas
}

\section{About «Book Sixteen» and «Book Seventeen» of the Comentarios de erudición, by Bartolomé Jiménez Patón: Lexical Notes}

\section{Juan Miguel Monterrubio Prieto}

Instituto de Estudios Hispánicos en la Modernidad (IEHM)

Universidad de las Islas Baleares

ESPAÑA

jm.monterrubio@uib.es

[Hipogrifo, (issn: 2328-1308), 4.2, 2016, pp. 251-266]

Recibido: 30-09-2016 / Aceptado: 10-10-2016

DOI: http://dx.doi.org/10.13035/H.2016.04.02.18

Resumen. El presente estudio examina parte del léxico del «Libro decimosexto» y del «Libro decimoséptimo» de los Comentarios de erudición, de Bartolomé Jiménez Patón, a raíz del hallazgo, hace una década, del tomo IV de esta magna obra que compendia los escritos del maestro manchego. Los datos demuestran que nuestro autor se sitúa en una doble vertiente: una, conservadora, sigue acudiendo a vocablos y a acepciones que ya debían de sentirse como arcaicos en el español clásico; otra, atenta las innovaciones, incorpora neologismos áureos e, incluso, introduce alguna acepción novedosa en voces existentes o concibe un vocablo original.

Palabras clave. Patón, léxico, neologismos, arcaísmos, historia del español. 
Abstract. This study analyzes part of the lexicon of «Book Sixteen» and «Book Seventeen» of the Comentarios de Erudición by Bartolomé Jiménez Patón, in light of the discovery, a decade ago, of volume four of this great work that constitutes a compendium of the writings of the prolific Manchegan author. The data gathered indicate that our author's lexicon is characterized by a curious duality: it is at the same time conservative, to the extent that it continues to resort to words and acceptations that doubtless were considered to be archaic in standard Spanish; and it is innovative as well, incorporating established Golden Age neologisms and occasionally introducing new meanings for extant words, as well as inventing new words of his own.

Keywords. Patón, Lexicon, Neologisms, Archaisms, History of the Spanish Language.

\section{INTRODUCCIÓN}

La aparición, en la última década del siglo anterior, de algunos textos del maestro Bartolomé Jiménez Patón ' dados por perdidos, reavivó el interés por este insigne humanista manchego. Dos de las obras recuperadas fueron el «Libro decimosexto» y el «Libro decimoséptimo» de los Comentarios de erudición, incluidos en el tomo IV de este magno proyecto que había de ser la recopilación de toda su obra. Tenemos la oportunidad de participar en la edición crítica² de este manuscrito, labor de la que se deriva el estudio aquí presentado.

La existencia de estas obras completas ha sido siempre conocida por los eruditos -el propio Patón y algunos de sus amigos se refieren a ellas en distintos lugares $^{3}$-, si bien no se había podido hallar ninguno de los ocho volúmenes, que

1. Acerca del maestro Patón, es fundamental la monografía de Madroñal, 2009. Sobre la cuestión bibliográfica, son clásicos los trabajos de Beardsley 1978 y 1986, y, más modernamente, Garau, 1993, y Madroñal 1993a, 1993b, 1996 y 2003. En cuanto a las ediciones modernas, debe citarse la publicación del Epítome de la Ortografía latina y castellana y de las Instituciones de la gramática española, 1965; de fecha más reciente, destacan la edición de los hasta entonces inéditos «Libro decimosexto» de los Comentarios de erudición, 2010 y El virtuoso discreto, 2014. Bosch, 2009, estudiando precisamente el mencionado «Libro decimosexto», da cuenta de cómo el dómine explicaba los autores griegos a partir de la traducción y comentario de las Odas de Horacio, mientras que Bosch, 2011, analiza su labor de traductor. Las ideas religiosas de Patón, aspectos de su humanismo y la figura del orador cristiano se tratan, respectivamente, en Garau 2012, 2014 y 2016, mientras que la regulación del uso de la cruz cristiana es estudiada en González, 2016. El léxico misógino y homófobo en las Declaraciones magistrales de Patón se examina en Monserrat, 2016. Finalmente, pueden verse dos acercamientos a la lengua del «Libro decimosexto» de los Comentarios de erudición en Monterrubio, 2013a y $2013 \mathrm{~b}$.

2. Hasta el momento, se ha publicado Bosch, Garau, Madroñal y Monterrubio, 2010, al margen de los diversos artículos sobre los Comentarios de erudición y de otras ediciones de textos del dómine manchego antes indicados. Actualmente, el mismo equipo de investigadores trabaja en la edición crítica, en un solo volumen, del «Libro decimoséptimo» y el «Libro decimooctavo».

3. Madroñal, 1996, p. 386. 
contienen cinco libros cada uno. Felizmente, Abraham Madroñal ${ }^{4}$ pudo recuperar hace unos años el mencionado tomo IV, que contiene del libro decimosexto al vigésimo. Se trata de un volumen manuscrito y, en parte, autógrafo de Jiménez Patón. Es probable que la reunión de la opera omnia del maestro se realizara hacia 1621.

El «Libro decimosexto» comprende los folios 1-122 e incluye el Libro tercero de las Odas de Quinto Horacio Venusino, traducidas y comentadas en lengua española. De la lectura del tomo IV se infiere que el autor dispuso una estructura donde pudieran insertarse los variados textos que habían de componer la obra. Así, en el «Libro decimosexto» hallamos a Laminio Sileno, trasunto del maestro, dirigiéndose a Portugal y trabando amistad con un instruido hidalgo lusitano quien, tras ofrecerle pernoctar en su casa, ruega le lea las lecciones que lleva consigo y le permita consultarlas; el «Libro decimoséptimo», folios 123-180, cuenta la llegada de Laminio a Salamanca y lo que allí sucedió.

El propósito de este trabajo es ofrecer algunas reflexiones sobre el léxico utilizado por Patón en los libros mencionados. En lo que respecta al «Libro decimosexto», pueden verse algunas consideraciones sobre el vocabulario de este manuscrito en otro lugar ${ }^{5}$. Aquí se añaden nuevas voces y se incluyen otras procedentes del «Libro decimoséptimo».

Para ello, se ha aprovechado la base documental académica -el Corpus de Referencia del Español Contemporáneo (CORDE), el Corpus del Español Actual (CREA) y el Corpus del Español del Siglo XXI (CORPES XXI)-, confrontándola, cuando así lo requería el examen, con repertorios de referencia como el de Coromines y Pascual ${ }^{6}$, los léxicos contenidos en el Nuevo tesoro lexicográfico de la lengua española (NT$L L E)$ o el diccionario de Segura?

\section{ESTUDIO LÉXICO}

\subsection{Voces arcaicas y voces poco habituales en época clásica}

El vocabulario de Jiménez Patón se decanta, en ocasiones, por las variantes tradicionales, procedentes de época medieval, frente a las formas más modernas que van abriéndose paso en el español clásico.

Así, por ejemplo, Patón opta siempre por reformación (fols. 81v, 124v, 140v, 155) ${ }^{8}$, voz usada desde época medieval (la primera documentación del CORDE es

\footnotetext{
4. Madroñal, 1996.

5. Jiménez Patón, Comentarios de erudición («Libro decimosexto»).

6. Coromines y Pascual, 2012. En adelante, Cor.

7. Segura, 2010

8. Una vez apuntada la numeración de los folios correspondiente a los Libros decimosexto y decimoséptimo, y para evitar nombrarlos repetida e innecesariamente, nos limitaremos en lo sucesivo a indicar los folios donde aparecen las palabras estudiadas.
} 
de 1445), frente a reforma, voz que va abriéndose paso en época clásica y que acabará imponiéndose en el español moderno.

Otro uso arcaico es el de felice, con e paragógica, muy probablemente sentida ya como arcaica en el español áureo, que se lee en cinco ocasiones en el manuscrito (fols. 10, 25v, 43, 49, 62, 127) por ninguna aparición de feliz en ambos libros. Aunque el Aut apunta que la forma con e paragógica se usa preferentemente en la poesía para ajustar los versos, el CORDE amplía su alcance, pues la registra en textos de géneros diversos. En cuanto a la distribución cronológica de estas formas, se observa que, antes del 1200, la base de datos no recoge casos de felice ni de feliz; en el s. XIII solo aparece, en diecisiete ocasiones, la forma apocopada; en el s. XIV se consignan doce casos de felice por solo uno de feliz; el s. XVI evidencia un equilibrio en el uso de ambas formas: trescientas veinticuatro apariciones de la forma arcaizante por trescientas cincuenta y ocho de la versión con apócope; en el s. XVII se impone definitivamente el uso de feliz: mil cuatrocientos setenta y dos casos atestigua el CORDE. Estos datos indican que felice no era, ni mucho menos, forma absolutamente extraña en la época de factura del manuscrito; sin embargo, hacía ya varios siglos que la e añadida, etimológica o no, era sentida como arcaica. Obsérvese, por otra parte, que el diccionario académico tuvo necesidad de mantener la forma -marcada como «poco usada», claro es- hasta su penúltima edición (la vigésima segunda).

Vegada (fol. 141) es también voz anticuada en época de Jiménez Patón: «La segunda es: cada vegada que el maestro derecho venga delante de algún juez que esté juzgando, débese levantar a él y servirle y recevirle que sea consigo».

Cor. observa que vez mantuvo un largo pulso con su derivado vegada (lat. vulg. *vicata), que es común al castellano y al portugués antiguos, al catalán y al occitano, y que está representado en hablas francesas, réticas e italianas. Añaden que, muy usual desde Berceo, Valdés ya recomienda sustituirlo por vez, pues la considera arcaica. Para el Aut es «Lo mismo que vez, pero hoy tiene menos uso.» Naturalmente, debe tenerse en cuenta que este repertorio se elabora casi un siglo después de la muerte del dómine manchego. En cualquier caso, ambas fuentes apuntan a que esta palabra era ya percibida como un arcaísmo en vida de Patón. No obstante, los datos del CORDE aún proporcionan, entre 1550 y 1650, ochenta y cinco apariciones en veintisiete documentos, prueba de que mantenía una cierta vigencia, si bien conviene hacer dos matizaciones: por una parte, siete de estas ocurrencias corresponden al Vocabulario de refranes y frases proverbiales, de Gonzalo Correas, donde se consignan expresiones que, por su naturaleza, retienen frecuentemente léxico de épocas anteriores; por otra parte, se trata de una palabra de uso muy común. Por supuesto, los casos de vez son abrumadores en el periodo de tiempo acotado, casi veinte mil. Así las cosas, Patón opta de nuevo por el vocablo más tradicional, que estaba ya perdiendo la partida con vez.

9. No obstante, véase cómo titula unos de sus libros el maestro manchego: Reforma de Trajes. Doctrina de fray Hernando de Talavera, primer arzobispo de Granada. Ilustrada por el Maestro Bartolomé Ximénez Patón, regente del estatuto de letras humanas en Villanueva de los Infantes. Enséñase el buen uso del tabaco (1638). 
Otra palabra, peorar (fol. 179v), poco usada y muy probablemente percibida ya como obsoleta en el español áureo, aparece también en los Comentarios de erudición: «Y he tenido por bueno el trabajo que he puesto y el don que ofrezco, por entender que ni por el tiempo se ha de envejecer ni por los sucesos ningunos peorar».

Ya se advierte en Cor. que no es forma muy común -frente al ampliamente extendido empeorar- pese a ser voz antigua según se atestigua en el CORDE, que sitúa la primera documentación en 1325-1335. Se registran veintiún casos de este verbo, en algunas de sus variantes conjugacionales, en este banco de datos, de los cuales la mayor parte son medievales - la última ocurrencia es de 1580. De hecho, esta palabra no se consigna en la lexicografía académica hasta la edición de 1803, y lo hace ya marcada como anticuada.

Algunas palabras, sin ser propiamente arcaicas, eran poco habituales en vida de Patón. Así sucede, por ejemplo, con batismal (157v): «También se procure saber qué son "iglesias catedrales", cuáles "metropolitanas", cuáles "collegiales", cuáles "parroquiales", cuáles "batismales"».

Esta forma del adjetivo, con reducción del grupo culto /-pt-/, no figura ni en Cor. ni en Segura (2010). Tampoco se recoge en la lexicografía académica, excepto en el DHLE 1933-36. El NTLLE da cuenta de su aparición en tres repertorios decimonónicos no académicos -Domínguez 1853, Gaspar y Roig 1853 y Zerolo 189510-, siempre remitiendo a bautismal, que es la voz del español moderno según se refleja en el CREA, donde es la única forma presente. El nombre del cual deriva el adjetivo hallado en el manuscrito, batismo, también con reducción del grupo culto latino, apenas tiene treinta y dos ocurrencias en el CORDE entre 1500 y 1700; baptismo, en cambio, muestra novecientas ochenta y una durante el mismo periodo, por mil ciento dieciséis de bautismo, la forma con vocalización de $/ p /$ agrupada ${ }^{11}$. Por otra parte, el adjetivo batismal no se documenta en el CORDE en época áurea, mientras que se obtienen veintitrés casos de bautismal y veinticuatro de baptismal. Así las cosas, se advierte la natural disputa entre el semicultismo, que vocaliza la consonante agrupada, y el cultismo, que conserva la asociación consonántica latina, que habría de decidirse en favor del primero, sin duda influido por el éxito paralelo de bautismo. En esta situación, no deja de sorprender que un autor tan próximo a la ortodoxia cristiana como Patón se incline por una forma, batismal, que debía de ser extraña a juzgar por los datos obtenidos, particularmente si se considera el carácter protocolario y conservador del léxico religioso.

También es destacable que Patón se refiera al mulso, nominalización del participio pasado de mulcēre, 'endulzar': queriendo encarecer el mulso hecho de vino y miel (fol. 80). El diccionario académico no registra esta voz hasta la duodécima edición, la de 1884. El CORDE muestra, en toda su extensión cronológica, cuarenta y tres casos en quince documentos (descartamos aquí las ocurrencias propiamen-

10. Por razones de simplicidad, no incorporamos a la «Bibliografía» de este trabajo los repertorios citados a partir del Nuevo tesoro lexicográfico de la lengua española (NTLLE), fácilmente accesibles mediante la consulta de este recurso electrónico.

11. Compárense estos casos con la serie lat. captivo, esp. cativo, cautivo (forma moderna). 
te latinas), y solo siete de ellos se recogen entre 1550 y 1650, prueba de que no era palabra demasiado común. Las primeras documentaciones de este cultismo se fechan hacia 1450, y suman diecinueve las apariciones hasta 1550. Posteriormente, los datos de los bancos textuales proporcionan solo diez casos desde 1650 hasta nuestros días. No obstante, la palabra se mantiene en la lexicografía académica hasta la actualidad, sin marca alguna que dé cuenta de su exiguo uso.

Otra voz infrecuente -abarcamiento (fol. 154) - halla acomodo en los Comentarios: «Por que en unas partes está recebido el término oecumenico, [...] declarando a todos su universalidad, generalidad y abarcamiento, si así se puede decir, pues todo lo comprehende y abraza».

Presente en Nebrija (1495) y ausente de Cor. -en la entrada abarcar, no figura entre sus derivados - y del Aut, para la segunda edición del diccionario académico (1780) abarcamiento es equivalente a abarcadura - que también falta en Aut y en Cor., pero no en Nebrija (1495)-, definida como «la acción y efecto de abarcar». Abarcamiento sigue en el DRAE desde entonces, y solo en la última edición (2014) se marca como «poco usada», repertorio del que ha desaparecido abarcadura (se mantuvo hasta la versión de 2001). Además, la lexicografía no académica también ha dado cuenta sistemáticamente de las dos voces.

Resulta llamativo, no obstante, que Patón recurra a este vocablo por cuanto los datos del CORDE proporcionan únicamente dos ocurrencias, y ambas del siglo xx $(1966,1970)$. No se trata, en todo caso, de un neologismo del maestro puesto que, como se ha apuntado, Nebrija lo consigna a finales del xv, pero conocer su uso en el «Libro decimoséptimo» aporta un dato más para la caracterización diacrónica de esta palabra, que, además, solo muestra una aparición en el CREA (1984). Por otra parte, tan exigua representación no parece justificar la sostenida presencia de abarcamiento en los repertorios léxicos del español, y aún menos la ausencia de marcas que señalen su escaso uso. Y en idéntica o más sorprendente situación se halla su sinónimo abarcadura, del que no se ofrece caso alguno ni en el CORDE ni en el CREA y que, sin embargo, ha figurado en la lexicografía académica hasta nuestros días.

En algunas ocasiones, el dómine manchego usa una voz en su sentido menos frecuente, como en caudaloso (fol. 130): «Y conociendo todo el mundo - particularmente las regiones habitadas de católicos- esta grande y perfeción escelente, acuden de las más remotas por mar y por tierra a hacer caudaloso empleo destos tesoros».

Se trata de una formación románica que aparece a principios del siglo XV. Esta voz, según el Aut, significa «muy rico y acomodado, lleno de bienes, hacienda y riquezas»; también se aplica el adjetivo al río que lleva mucha agua y va muy profundo. Patón, no obstante, usa esta voz en el sentido menos común, según observa el Aut: «Estimable, apreciable, conveniente y oportuno para granjear y hacer caudal». Debe entenderse la expresión hacer caudal como «hacer caso, prestar atención» (Cor.). Este significado de caudaloso debió de ser paulatinamente olvidado, pues ya no se registra en el repertorio académico de 1780. 
Se acredita, ya desde el primer registro del CORDE (1406-1411), el significado que el Aut marca como menos habitual y que es el usado en el «Libro decimoséptimo»:

E el maestre de Santiago, don Lorenço Suárez, le dixo:

-Aquí está Alonso Fernández Melgarejo, que comarca aquí e es caudaloso, el qual es bien pertenesciente para vuestro seruiçio e para la tener (La anónima Crónica de Juan II de Castilla).

De hecho, las tres ocurrencias que figuran en la Crónica de Juan II de Castilla muestran el mismo sentido. De las primeras catorce, todas de época medieval, dos corresponden al significado de 'persona rica', cuatro a 'persona valiosa' y cinco a 'río profundo'. Entre 1501 y 1700 se registran mil cuatrocientos once casos, número que desciende a trescientos trece durante el siglo XVIII, estos últimos casi siempre aplicados a río. Ello concuerda con la desaparición del sentido de 'persona valiosa' en la edición del diccionario académico de 1780.

En enfermo (fol. 90), sin ser propiamente un arcaísmo, se advierte en una ocasión el uso próximo al sentido etimológico de la voz enfermo (<infirmus), más infrecuente que el significado moderno: «Entre los demás bienes que le aseguran le vernán de la mano de Dios por ofrecerle con limpias manos cualquier pobre sacrificio, es la salud de sus hijos, especialmente en el otoño, que es el tiempo del año más enfermo», donde hay que entender el mencionado adjetivo como «inestable» o «no firme».

\subsection{Voces neológicas}

El manuscrito que manejamos proporciona ciertos neologismos que merecen atención.

Uno de ellos es vice Cristo (fol. 135v): «Y después desto, en todas las ocasiones de honra que el mismo Dios dio a los suyos, lo vejaminaba. Había de priviligiar a San Pedro y hacelle vice Cristo de su Iglesia y quería comenzalle a hacer participante de los actos de su divinidad».

Esta formación prefijal no se documenta ni en el NTLLE ni en el CORDE. El Aut, no obstante, se refiere a vice-Dios: «Título honorífico y respetuoso que se da al Sumo Pontífice y a los reyes y monarcas por estar en lugar de Dios en la tierra», voz únicamente representada en dos ocasiones en el CORDE, y solo una de ellas de época clásica (1610). Patón parece optar por una variante neológica con el mismo significado (al menos en los contextos que manejamos), como puede observarse. Desde el punto de vista formal, se advierte que el Aut presenta la formación con un guion intermedio, mientras que en el manuscrito del «Libro decimoséptimo» aparecen separados el prefijo y la base.

Alguna palabra no es propiamente un neologismo del dómine manchego, pero sí demuestra su atención a los vocablos que inician su andadura por esas fechas. 
Un caso ilustrativo es el de donosidad (fol. 156v): «Destos era uno a quien le sucedió lo que diré, que, por que pasó delante de mí y ser cuento que con la donosidad que tiene hace a nuestro propósito, lo he de referir».

Esta palabra, construida sobre el adjetivo donoso, se define en el Aut como «Agraciado, pulido, aseado, chistoso, y que atrae la vista y la voluntad por lo gustosa que es su conversación». Esta caracterización, que aúna cualidades diversas, apunta a la persona atractiva y ocurrente. Es precisamente esta segunda condición, la de agudeza humorística, la que parece consolidarse en la palabra derivada que nos ocupa, delimitada así en el citado repertorio: «Donosura, gracia y chiste», así como en su competidora, también derivada del mismo adjetivo, donosura: «Donaire, chiste, gracejo.» En Cor. se da noticia de la existencia de un antiguo donosía, de idéntico significado, ausente en el Aut pero consignado desde la tercera edición del diccionario académico (1791) hasta la vigésima primera (1992), última en la que aparece. De modo inopinado, este vocablo se mantuvo largo tiempo en el DRAE pese a contar, únicamente, con dos apariciones en el CORDE (ambas en la segunda mitad del siglo XV) y no haber constancia de ella en el CREA.

En cuanto a donosidad, la voz que elige Patón en el «Libro decimoséptimo», muestra diecisiete ocurrencias, todas en el apretado periodo que transcurre entre 1617 y 1648 -a las que hay que añadir dos apariciones esporádicas a mediados del siglo XX-, por lo que cabe pensar que la palabra era un flamante neologismo cuando el maestro lo incorpora a su obra -recuérdese que los Comentarios de erudición se debieron de recopilar hacia 1621, aunque no vieran la luz hasta 1628. Por lo demás, no hay más rastro de ella en los bancos de datos académicos CREA y CORPES XXI. El Aut, por su parte, advierte de que «tiene poco uso», nota que no incluye, en cambio, en la entrada correspondiente a donosura, de idéntico significado. Resulta curioso, por tanto, que el CORDE solo proporcione una ocurrencia de esta última palabra en época clásica (1690, que supone, además, la primera documentación) de entre los ciento veinte casos registrados; el CREA, por su parte, arroja una muy discreta presencia en el español moderno, únicamente veinticuatro apariciones.

Otra innovación léxica que aprovecha Patón es buleto (fol. 141v): «Tienen muchas esenciones, inmunidades, privilegios, los que yo no puedo referir y será fácil ver en los buletos apostólicos y gracias de reyes hechas a las Escuelas».

El Aut define así buleto: «Diminutivo de bula. El breve apostólico que regularmente se da para concesión de algún privilegio o para dispensación de algún impedimento en materia de matrimonio o de Órdenes sagradas o para otros fines». Según Cor., es voz que se usa entre los siglos XVII y XIX, lo que se ve confirmado por los datos del corde, que proporcionan un caso de finales del XVI, trece del XVII, uno del XVIII y cuatro del XIX, al tiempo que la consulta al CREA no arroja ninguna ocurrencia posterior. Por tanto, de nuevo hallamos al maestro manchego atento a las novedades léxicas.

Perseguida (fol. 149) es otra formación neológica: 
mirad, por vuestra vida, que llevan mis doncellas aunque tiernas y bellas y a los mancebos desta perseguida, con muy grave improperio a esclavitud prolija en cautiverio.

Esta palabra aparece en uno de los poemas de las Lamentaciones, atribuidas a Jeremías, por lo que su presencia puede responder a la necesidad de mantener la rima. Está construida mediante el sufijo deverbal -ida, con el significado de 'acción y efecto', como en embestida o acogida. Es voz que no se documenta en Cor. ni ningún repertorio del NTLLE ni en el CORDE. El español, no obstante, conoce desde época medieval el semicultismo persecución -muy frecuente- y el románico -menos habitual- perseguimiento.

También es construcción neológica cejeándose (fol. 151v):

«Concilio» se dijo tomando el nombre de los romanos, que a sus juntas le daban este nombre, o consilium, por que aquí vienen de conformidad todos a ser de un parecer y consejo. Dicen decirse a cilia, por las cejas, por que, cejeándose, declaraban las intenciones.

El verbo cejear(se), 'mover las cejas dando a entender un parecer', que hallamos en el manuscrito, no figura en Cor., ni en el $D H L E$, ni se documenta en ningún repertorio del NTLLE ni se registra en el CORDE o en el CREA o en el CORPES XXI. Puede señalarse, pues, al menos hasta donde hemos podido consultar, que estamos ante un neologismo de Patón formado mediante la adjunción del sufijo frecuentativo - ear a la base nominal ceja, lat. člia, 'cejas'.

Otro neologismo incorporado a su obra por el maestro manchego es enfadoso (fol. 54): si acaso te detuviere el enfadoso portero, escápate. Según Cor., el verbo enfadar era raro hasta finales del siglo XVI, pues el verbo patrimonial del castellano era enojar, que es todavía casi el único empleado en América. Este mismo repertorio sitúa la primera aparición de enfadoso en 1570, si bien los datos del CORDE retrasan esa fecha hasta 1547 o, quizá, 1536. Se lee, asimismo, que «enfadoso significó 'aburrir', 'hastiar', 'cansar' hasta el siglo XVIII»; sin embargo, este ejemplo del CORDE, fechado en 1591 parece exhibir ya el significado moderno «fastidioso, molesto»:

es este sabor tan cierto en toda ella que apenas ay miel que comer se pueda sin cozerla primero, para que con el tal cozimiento pierda el enfadoso y molesto sabor agrio que consigo tiene (Juan de Cárdenas, Primera parte de los problemas y secretos maravillosos de las Indias, México).

si bien esta acepción convive, en el mismo libro, con un caso acorde con lo indicado por Cor:: «y que el cuerno del unicornio, puesto delante de qualquiera veneno, suda y otras mil estrañas propiedades, que por no ser enfadoso dexo de dezir». 
Patón conoce el escasamente extendido neologismo domestiquez (fol. 135v) y lo incorpora a su prosa: «y porque el que quiere saber ha menester trabajar con domestiquez y sufrimiento como el buey puesto en el yugo».

Esta palabra, con un sufijo que aporta 'cualidad de' a la base de derivación, conforma, junto con domestiqueza y domesticidad, una curiosa terna de voces con sufijos de sentido equivalente. El Aut apunta que domestiquez es «lo mismo que mansedumbre» -lo cual se compadece bastante bien con el sentido que parece querer Patón en el «Libro decimoséptimo»-, que «tiene poco uso» y que «en lo antiguo se decía domestiqueza». En Cor. se indica que el raro domestiqueza (hacia 1440) proviene del italiano domestichezza y se le atribuye el sentido de 'familiaridad'. Los datos del CORDE confirman que tanto domestiqueza (siete casos entre 1384 -esta fecha adelanta más de cincuenta años la primera documentación señalada por Cor.- y 1650, luego desaparece de los documentos) como domestiquez (cuatro casos, todos entre 1611 y 1624) fueron palabras de escaso uso.

En Cor. se señala, además, la existencia de otra versión sufijada, domesticidad, de la que no indica significado ni fecha de primera documentación. La lexicografía académica no recoge esta voz hasta 1791, con el sentido de «afabilidad, suavidad en el trato». El DRAE 2014 define domesticidad como «cualidad de doméstico», si bien no se halla entre las acepciones de doméstico, su base de derivación, ninguna que sustente la interpretación que se ofrece en la primera documentación lexicográfica académica.

En suma, la voz italiana entró como préstamo en la Edad Media con el sentido de 'familiaridad' y se adaptó como domestiqueza; se usó luego, junto a la variante domestiquez, con el significado de 'mansedumbre' aplicado a personas. La formación domesticidad, más moderna, surge a finales del siglo XVIII para indicar 'afabilidad'; finalmente, la palabra ha abandonado este sentido y es la construcción que permite nombres abstractos de cualidad a partir de la base adjetiva doméstico.

Alucinar (fol. 138v) es un neologismo interesante: «¿Cuándo comenzasen los grados? No osaré yo afirmar con determinada certeza del tiempo, aunque sí me atreveré a alucinar algunas cosas de que se puede hacer probable conjetura, poco más o menos».

Así se define este verbo en Cov.: «Es como adivinar una cosa que ni se sabe ni se entiende bien, al modo del que entre las dos luces, o de la tarde o de la mañana, viendo una cosa le parece otra de la que es». Cor. indica que esta voz, cuya primera aparición se documenta en 1499, procede del lat. ālūcĭnari; por tanto, es un latinismo neológico, y así lo considera aún Cov. Apunta también Cor. que, entre los siglos xv y xvii, usado como intransitivo, conserva el sentido etimológico de 'sufrir alucinación'. En el NTLLE'12 se registra una definición que parece inspirarse en la de Cov.: 'To guess at uncertainties, as on fees betwixt Light and Darkness'; además, nota que es «A word little used but by Poetical Writers».

12. Stevens, A new Spanish and English Dictionary. 
La primera edición del Aut no recoge este verbo, pero sí la segunda (1770) - de la que solo vio la luz el tomo A-B- donde se define como «Ofuscar, confundir». Terreros (1786) escribe: «Aturdir, entorpecer». Ambas definiciones implican un sentido transitivo distinto del etimológico que pervive en época clásica, si bien el repertorio académico apunta que se usa más a menudo como recíproco. El DRAE 1884 dice que alucinar es «Perturbar la razón con engaño de los sentidos algún daño físico o alguna influencia moral»y, figuradamente, «Ofuscar, seducir o engañar». En el DRAE 1925, la acepción 1. es 'Ofuscar, seducir o engañar', es decir, la que la lexicografía académica había venido considerando de carácter metafórico, al tiempo que consigna el significado intransitivo etimológico de 'Confundirse, ofuscarse, desvariar' indicando que se trata de un sentido desusado. Es en el DRAE 1992 donde se añade, a estas dos últimas, una novedosa: «Sorprender, asombrar, deslumbrar», de uso pronominal también, que es la que predomina en el español actual. Resulta curioso que este verbo, de origen oscuro en latín según Cor., dé pie constantemente a establecer una relación pseudo-etimológica con la palabra luz: así lo hace Cov., quizá alucinando, precisamente, en el sentido propio de esta voz, y así invita a pensarlo también la última acepción académica mencionada, que incluye la idea de 'deslumbrar', de la familia de lumen, -inis, 'luz', bien que en una interpretación figurada.

En conclusión, el significado que se consigna en Cov. es el único aplicable al uso observado en el «Libro decimoséptimo», pues no es posible entender aquí alucinar como 'ofuscar, confundir o desvariar' ni tampoco 'sorprender o deslumbrar', interpretación que se ve corroborada por el NDHE (1960-1996), que apunta en la tercera acepción de este verbo: «tr. Imaginar. intuir. Este diccionario ilustra con este ejemplo: «Lo que Pitágoras y Demócrito (siendo Sabios) de la inmortalidad del alma soñaron y alucinaron, el negro y el aldeano con la Fe lo afirman» (1600 Rebolledo, Fray L. Orac. I 395v)».

El uso transitivo documentado en el manuscrito estudiado -aunque sí me atreveré a alucinar algunas cosas de que se puede hacer probable conjetura-, por otra parte, matiza la observación de Cor., según la cual «en los siglos XV-XVII se emplea como intransitivo, alucinar 'sufrir alucinación', según el uso latino». Además, la fecha de primera documentación que pudo hallar este mismo diccionario -1499- se ve modificada por los datos del CORDE, que registran una aparición en 1340 en un documento notarial (Anónimo, Traducción de la versión occitana del Fuero de Jaca por García Martínez, notario de Villafranca de N ...). Patón, si bien en el uso menos común, como se ha visto, recurre a este latinismo neológico que, tras la primera documentación medieval, aislada, se recoge tan solo seis veces en el CORDE en época clásica antes de la muerte del maestro manchego.

Las formas acivile y urbane (fol. 127), que aparecen juntas en el texto, revelan un uso innovador y una creación original, respectivamente, del humanista manchego:

Pues, ¿quién habrá tan duro que no se enternezca, tan montaraz que no se acivile y urbane, tan rebelde que, mandado, no obedezca y, rogado, no estime la honra que le hacen, señalándole paraninfo de la gratitud que todos debemos levantar con increíbles encomios a las estrellas? 
Sorprende que Patón recurra aquí al verbo acivilar, «Hacer baja y vil una cosa», según el Aut, pues se espera un sentido que se contraponga a montaraz y que concuerde, además, con el que cabe interpretar en urbanar (en principio, acorde con la intención de la frase si se lee así: 'hacer urbano, civilizado', por contraposición a agreste, incivil'), verbo, este último, que no se registra ni en el Aut ni en el CORDE.

Civil, documentado, según Cor., desde 1169, proviene de cīvilis, 'propio del ciudadano', 'político'. Indica este mismo repertorio que civil se opone a militar en términos administrativos. El Aut observa todavía que, en el sentido de 'sociable, urbano' o 'civilizado', no tiene uso en castellano, solo admite civil como opuesto a criminal en el estilo forense (lo mismo hace Cov.) y advierte que el significado corriente es «desestimable, mezquino, ruin y de baxa condición y procederes», acepción actualmente anticuada, pero de la que hay multitud de ejemplos desde la Edad Media hasta el siglo XVII. Se apunta en Cor. que tal sentido «debe explicarse como consecuencia del significado de 'caballero' que tomó el lat. mīles en la Edad Media, de donde vino el que civilis, como opuesto a militaris 'propio del caballero', pasara a significar 'villanesco, propio del no caballero'», y fecha acivilar (o, también, acevilar) 'envilecer' en los siglos XVI-XVII.

Así, el significado de acivilar no casa con el que presumimos en urbanar, a quien está ligado por la conjunción y, a no ser que se pretenda que Patón adopta un uso novedoso, de conciencia etimológica, donde atribuye al adjetivo de base de este verbo un sentido primario, opuesto a 'grosero, ineducado, bajo o vil'.

Por otra parte, urbanar, que no se halla ni el NTLLE, ni en el CORDE ni se registra en Cor., está formado sobre el adjetivo urbano (lat. ŭrbānus 'propio de la ciudad'), que se documenta hacia el $2^{\circ}$ cuarto de siglo XV. El Aut indica que este adjetivo «se toma también por cortesano, atento y de buen modo»; no registra, este repertorio, el moderno urbanizar «hacer urbano y sociable a uno» (DRAE 1899). Este sentido es el que se interpreta en el urbane que escribe el maestro Patón, en lo que cabe señalar como un neologismo propio del autor manchego.

El CORDE documenta por primera vez un verbo urbanizar en 1618 (Esteban Manuel de Villegas, Eróticas o amatorias):

Cultura de pradera mostraba la ciudad de Polinices; pero voces felices la urbanizaron luego, de manera que luego dió por duros la juventud argólica sus muros. No toscas argamasas merecieron allí tener asiento, que, artífice el acento, añudó las almenas y las basas con lazos tan cabales, como si fueran puntos centruales. 
Nótese que el sentido de este verbo, formado sobre la misma base adjetiva que urbanar, es, en los versos aducidos, el de 'crear o mejorar construcciones allá donde solo hay tierra o arquitectura precaria', no el de 'educar o suavizar los modos de una persona', como parece invocar el uso del maestro manchego. Habrá que esperar hasta la segunda mitad del s. XIX para comprobar el asentamiento de este verbo, agazapado en estado latente durante casi doscientos cincuenta años en nuestra lengua, como certifica su primer registro lexicográfico (DRAE 1899). Conviene advertir que esta documentación lexicográfica ofrece dos acepciones: «Hacer sociable y urbano a uno» y "Convertir en poblado una porción de terreno», es decir, ubica en primer lugar el sentido metafórico que, con el paso de las décadas, ha ido perdiendo uso en favor del más próximo al etimológico.

La voz notomía (fol. 129v) presenta algunas particularidades: «Y no piensen algunos que he olvidado la Medicina, pues la notomía que de ordinario se hace descubre lo que sus dotores se precian de ser los más aventajados del mundo».

Extrañamente ausente del Aut, -es voz usada, por ejemplo, en la primera y en la segunda parte del Quijote-, no asoma por el diccionario académico hasta 1899 con el sentido de 'esqueleto', adivirtiéndose que es voz anticuada, y en la siguiente edición, la de 1914, se añade que vale por 'anatomía', significado también obsoleto. No obstante, sí la registra Terreros y Pando (1787) en su monumental repertorio, aunque con una descripción singular: «Notomía: Voz burlesca. Lo mismo que Anatomía». Y este insigne jesuita ya entiende la Anatomía como la «ciencia, arte y conocimiento de las partes del cuerpo humano o de algún animal, en orden a su disección, y curativa. También se llama anatomía a la misma disección».

El CORDE, por su parte, ofrece numerosos ejemplos del español clásico donde notomía equivale a 'disección del cuerpo humano', sin rastro alguno, por cierto, del matiz irónico o burlesco, si bien no faltan casos en los que significa 'anatomía' en el sentido moderno de 'ciencia que estudia la estructura y forma de los seres vivos'. En el texto del «Libro decimoséptimo», ambos significados pueden ser apropiados para explicar la frase en que se inserta la palabra considerada, ya que, por una parte, el verbo 'hacer' invita a pensar en un sujeto con idea de 'acción', mientras que, por otra, el sentido de 'anatomía' se ajusta bien a la coherencia del discurso que desarrolla aquí Patón enunciando las diversas materias que se enseñan en la Academia de Salamanca.

El modo de usar la voz hidropesía (fol. 172) por parte de Patón revela su conciencia de los mecanismos figurativos que dan lugar a sentidos neológicos:

Y esto he dicho, forzado de importunaciones, por no dar en descortés, que mucho gustara de escusarme porque temo el poco crédito que esta dotrina y mis razones han de hallar en los enfermos desta pestilencia de codicia, raíz de todos los males, sequía que ni se llena ni harta, sino que, al paso del aumento, crece su deseo como hidropesía.

El Aut sigue el parecer de Cov., según el cual «algunas veces se toma por avaricia, porque el hidrópico, por mucho que beba, nunca apaga su sed, ni el avariento, 
por mucho que adquiera, su codicia». Se entiende bien la traslación que da lugar al sentido metafórico, por más que proceda de una creencia, que hoy se sabe errónea, según la cual la persona afectada de hidropesía lo está por beber en exceso.

Cor. indica que hidropesía está «tomado del b. lat. hydropisia, lat. hydropisis íd.,

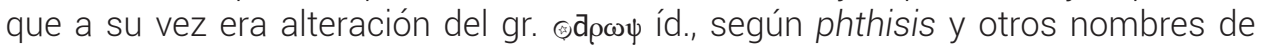
enfermedad». En el DRAE 1780 se lee que es «Enfermedad causada por un conjunto de aguas que se hace en alguna parte del cuerpo, la cual suele proceder de beber en exceso y causa hinchazón [...]. Metafórico: deseo desordenado de riquezas». El sentido figurado se conserva en el repertorio académico hasta la edición de 1817, mientras que la acepción médica sigue registrándose, con marca, en la actualidad.

El uso lexicalizado que hallamos en nuestro manuscrito procede, precisamente, de un contexto donde se habla de la codicia, en sentido estricto; por otra parte, el hecho de que la voz aparezca en una estructura comparativa - «y mis razones han de hallar en los enfermos desta pestilencia de codicia, raíz de todos los males, sequía que ni se llena ni harta, sino que, al paso del aumento, crece su deseo como hidropesía»- permite deducir que el autor advierte, consciente, la traslación metafórica que se ha operado en la palabra, lo que vuelve a evidenciar la exquisita formación lingüística de Patón.

\section{CONCLUSIONES}

El examen de las voces seleccionadas pone de manifiesto dos caracteres aparentemente contradictorios en la prosa del maestro Patón -en realidad, dos caras de la misma moneda- que se explican por su sólida formación lingüística. Por una parte, se observa una inclinación al mantenimiento de ciertas palabras o acepciones medievales, al tiempo que se decanta con frecuencia por los sentidos menos habituales en otras; por otra, se revela la mano del humanista atento, sensible a los significados innovadores de palabras instaladas desde largo periodo en el idioma, a los neologismos de su época e, incluso, a la creación de voces originales. En cualquier caso, faltan estudios acerca del supuesto incremento excepcional del caudal léxico en época áurea, pues el instrumento de referencia utilizado hasta hace escasos años para la datación era el Aut., cuyo acervo se nutre, preferentemente, de autores de los Siglos de $\mathrm{Oro}^{13}$. Además, quizá no siempre se han aprovechado como merecen las noticias de primeras documentaciones aportadas en el Cor., al margen de los naturales yerros de los que una obra de ese calibre no puede quedar exenta. Confiamos en que estas breves notas léxicas aporten alguna luz sobre el devenir de las palabras aquí presentadas. 


\section{BIBLIOGRAFÍA}

Beardsley, Theodore, «Bartolomé Jiménez Patón y Marcial: el problema bibliográfico», Libro-homenaje a Antonio Pérez Gómez, Cieza (Murcia), La Fonte que mana y corre, 1978, vol. I, pp. 91-114.

Beardsley, Theodore, «Bartolomé Jiménez Patón: The "Lost" and Unknown Works», en Renaissance and Golden Age Essays In Honor of D. W. McPheeters, ed. Bruno M. Damiani, Maryland, Scripta Humanistica,1986, pp. 1-25.

Bosch, María del Carmen, «Los autores griegos en el libro decimosexto de los Comentarios de erudición, de Bartolomé Jiménez Patón», Faventia, 31, 1-2, 2009, pp. 227-241.

Bosch, María del Carmen, «Pedro Ambrosio de Onderiz y Bartolomé Jiménez Patón, traductores de la Primera Lamentación de Jeremías», Studia Philologica Valentina, 13, 10, 2011, pp. 231-248.

Coromines, Joan y José Antonio Pascual, Diccionario crítico etimológico castellano e hispánico (1980-1991) [cd-rom], Madrid, Gredos, 2012.

Correas, Gonzalo, Vocabulario de refranes y frases proverbiales (1627), ed. Louis Combet, Madrid, Castalia, 2000.

Garau, Jaume, «El virtuoso discreto, un libro inédito de Bartolomé Jiménez Patón», Criticón, 59, 1993, pp. 67-82,

Garau, Jaume, «Ideas religiosas del Maestro Bartolomé Jiménez Patón (1569-1640) en El virtuoso discreto [C. 1629-1631]», Hispania Sacra, 64, 129, 2012, pp. 237-258.

Garau, Jaume, «El humanismo de Bartolomé Jiménez Patón a la luz de nuevos textos», Rilce, 30, 2, 2014, pp. 359-382.

Garau, Jaume, «La figura del orador cristiano en el Perfecto predicador (1612), de Bartolomé Jiménez Patón», Criticón, 124, 2015, pp. 137-152.

González, Juan Carlos, «De cruce Christi representationes in aureum saeculum: Ribera, Valencia, Patón et aliii», Hispania Sacra, 68, 38, 2016 (en prensa).

Jiménez Patón, Bartolomé, Epítome de la Ortografía latina y castellana. Instituciones de la Gramática española, ed. Antonio Quilis y Juan Manuel Rozas, Madrid, CSIC, 1965.

Jiménez Patón, Bartolomé, Elocuencia española en arte, ed. Francisco José Martín, Barcelona, Puvill, 1993.

Jiménez Patón, Bartolomé, Comentarios de erudición («Libro decimosexto»), ed. $M^{a}$ del Carmen Bosch, Jaume Garau, Abraham Madroñal y Juan Miguel Monterrubio, Madrid/Frankfurt, Iberoamericana/Vervuert/CSIC, 2010.

Jiménez Patón, Bartolomé, El virtuoso discreto, ed. Jaume Garau y $\mathrm{M}^{\mathrm{a}}$ del Carmen Bosch, Madrid/Frankfurt, Iberoamericana/Vervuert, 2014.

Madroñal, Abraham, «Aportaciones al estudio del maestro Jiménez Patón (dos obras inéditas y casi desconocidas)», Criticón, 59, 1993a, pp. 83-97. 
Madroñal, Abraham, «Una autobiografía inédita del maestro Jiménez Patón», Boletín de la Real Academia Española, 260, 1993b, pp. 553-567.

Madroñal, Abraham, «Los Comentarios de erudición del Maestro Jiménez Patón, unas obras completas supuestamente perdidas», Bulletin Hispanique, 98, 1996, pp. 385-395.

Madroñal, Abraham, «Obras "perdidas" de Patón y otros autores en la biblioteca del primer director de la Real Academia Española», Boletín de la Real Academia Española, 288, 2003, pp. 195-253.

Madroñal, Abraham, Humanismo y filología en el Siglo de Oro. En torno a la obra de Bartolomé Jiménez Patón, Madrid/Frankfurt, Iberoamericana/Vervuert, 2009.

Monserrat Roig, Catalina, «Misoginia y homofobia en las Declaraciones magistrales de Bartolomé Jiménez Patón», en Pensamiento y literatura en los inicios de la Modernidad, coord. Jaume Garau, New York, IDEA, 2016 (en prensa).

Monterrubio, Juan Miguel, «Aproximación a la lengua del "Libro decimosexto" de los Comentarios de erudición, de Bartolomé Jiménez Patón», Rilce, 29.1, 2013a, pp. 57-75.

Monterrubio, Juan Miguel, «Encrucijada de normas: los tiempos y los modos verbales, y la estructura del predicado en el "Libro decimosexto" de los Comentarios de erudición, de Bartolomé Jiménez Patón», Hipogrifo, 1.2, 2013b, pp. 157-168.

Real Academia Española, Banco de datos (CORDE), Corpus diacrónico del español. Disponible en línea: <http://www.rae.es>.

Real Academia Española, Banco de datos (CORPES XXI), Corpus del Español del Siglo XXI (CORPES). Disponible en línea: <http://www.rae.es>.

Real Academia Española, Banco de datos (CREA. Versión anotada), Corpus de referencia del español actual. Disponible en línea: <http://www.rae.es>.

Real Academia Española, Diccionario histórico de la lengua española (1933-1936) (DHLE). Disponible en línea: <http://www.rae.es>.

Real Academia Española, Diccionario de la lengua española, Madrid, Espasa, 2014.

Real Academia Española, Nuevo tesoro lexicográfico de la lengua española (NTLLE). Disponible en línea: <http://www.rae.es>.

Segura Munguía, Santiago, Nuevo diccionario etimológico latín-español y de las voces derivadas, Bilbao, Universidad de Deusto, 2010.

Stevens, John, A new Spanish and English Dictionary, Londres, George Sawbridge, 1706.

Terreros y Pando, Esteban de, Diccionario castellano con las voces de ciencias y artes y sus correspondientes en las tres lenguas francesa, latina e italiana..., Madrid, Viuda de Ibarra, 1786-1788.

Verdonk, Robert, «Cambios en el léxico español de la época de los Austrias», Historia de la lengua española, coord. Rafael Cano Aguilar, Barcelona, Ariel, 2004. 